\title{
Asset-Liability Management for Long-Term Insurance Business
}

\author{
Hansjörg Albrecher, Daniel Bauer, Paul Embrechts, Damir Filipović, \\ Pablo Koch, Ralf Korn, Stéphane Loisel, Antoon Pelsser, \\ Frank Schiller, Hato Schmeiser, Joël Wagner
}

\begin{abstract}
This is a summary of the main topics and findings from the Swiss Risk and Insurance Forum 2017. That event gathered experts from academia, insurance industry, regulatory bodies, and consulting companies to discuss past and current developments as well as future perspectives in dealing with asset-liability management for long-term insurance business. Topics include valuation, innovations in insurance products, investment, and modelling aspects.
\end{abstract}

\section{Introduction}

During the past decades, major changes have taken place in the way risk is assessed and managed in the insurance industry. This is in part due to the emergence of economic solvency regimes such as Solvency II and the Swiss Solvency Test as well as the development of accounting standards that are closer to an economic view. One of the key changes has been the identification of the risk of a mismatch between assets and liabilities as one of the most critical risks to which insurers writing long-term business are exposed to. Insurers are liabilitydriven financial intermediaries and their investment activity needs to be guided by its purpose, which is to ensure that claims can be met when they are due. That is, the liability structure is the benchmark for a successful asset liability management of an insurer.

However, determining this liability benchmark, and managing towards it, is challenging in practice and there are a variety of undesirable and unavoidable risks that insurers face in this context. We list here a few, which are particularly prominent for long-term business such as life insurance:

- Genuinely risk-free assets in fact do not exist and government bonds may not always be a sufficient proxy.

- The volume of outstanding insurance liabilities significantly exceeds the available volumes of government bonds.

- The maturities of future claims often significantly exceed the maturities of instruments available in the market.

- Insurance markets are incomplete under hedging with basic financial instruments.

- Liability cash flows are path-dependent due to embedded options such as minimum rate guarantees, management and regulatory rules such as policyholder participation, and policyholder behavior such as lapsing.

- The current low, and in certain cases even negative, interest environment may render some aspects of the underlying valuation methodology questionable. 
At the same time, dealing with such challenges leads to interesting academic and practical questions. It was the purpose of the Swiss Risk and Insurance Forum 2017 to gather the latest views from both academia and the industry on this topic. In this paper, we summarize the main findings and discussions. However, this summary does not necessarily reflect the views of all participants of the workshop. This was the third workshop of the Swiss Risk and Insurance Forum. The previous two were on Old Age Provision: Past, Present and Future in 2016, see Albrecher et al. (2016), and on Regulation and Risk Measurement in 2014, see KochMedina et al. (2014).

The remainder of the paper is organized as follows. Section 2 deals with valuation, and in Section 3 the topic is discussed in terms of insurance products and possible innovations. Section 4 then addresses investment, and finally Section 5 discusses some particular issues that arise in the area of modelling in this context.

\section{Valuation}

In the insurance industry valuation is one of the key processes for monitoring and steering business. The objective of valuation is to provide a (or if possible the only) market or fair value for assets and liabilities for the economic balance sheet to support management decisions. To enable consistent steering of a company, valuation should form the basis for all quantitative assessments in the economic balance sheet, which include

- fair value assessment of asset and liability portfolios;

- reserving (especially for future IFRS17); and

- risk capital calculations.

Whereas for pricing it might be important to use more detailed and granular models to reflect special product features, in valuation the in-force portfolio is well known and stable, and it is often possible to simplify models and only use aggregated assumptions. Even when in pricing sometimes completely different methods like psychological pricing or differential pricing are used to achieve an optimal impact in the market, it has to be clear for the pricing department how the portfolio will eventually be evaluated in the economic balance sheet, as the aggregate assumptions and model features and their calibration have to be consistent.

\subsection{What makes valuation so difficult?}

For insurance liabilities, deep and liquid markets do not exist. Therefore, valuation - or, more precisely, market-consistent valuation - of products and portfolios cannot be based on market prices alone but has to be derived from models. These models have to assess the value of future cash flows (premiums the insurer receives, claims and costs the insurer has to pay) and the result is the current present value of these cash flows.

For that purpose, we can distinguish at least three different components of these cash flows: 


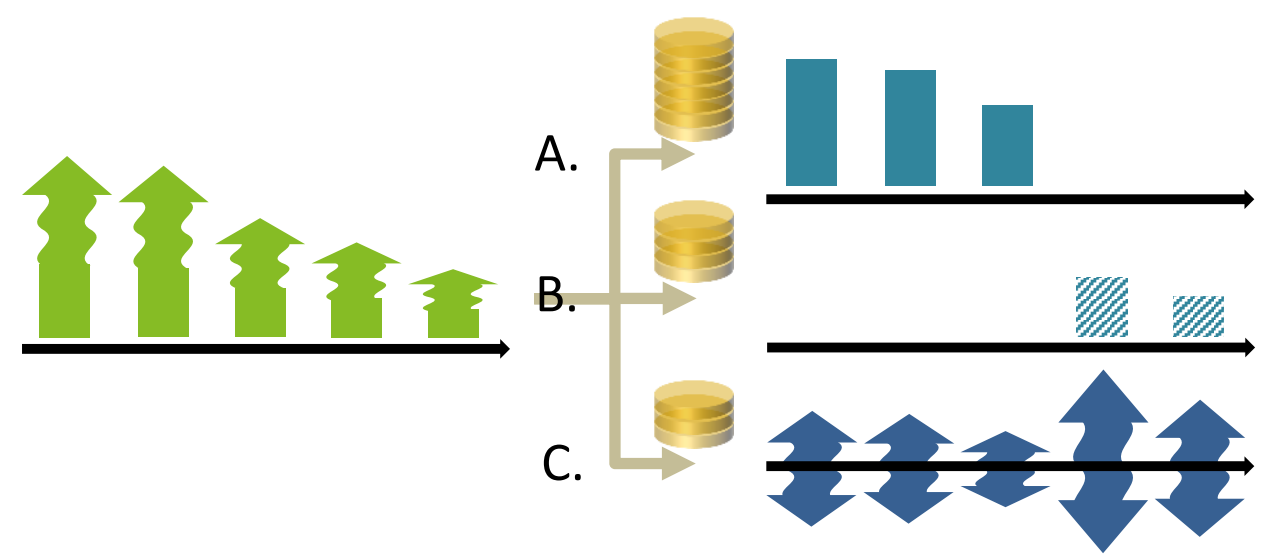

A. The component of the cash flow that can be perfectly replicated in all possible states of the world by existing financial instruments.

B. The component of the cash flow that can be perfectly replicated in all possible states of the world by future cash flows, but only with future financial instruments that are not yet traded.

C. The remainder, the component that cannot be produced with existing and future financial instruments.

Table 1 in Knispel et al. (2011) provides examples of risks in categories A (e.g., equity, interest rates with short to medium term, etc.), B (e.g., long-term interest rates or volatilities), and $C$ (systematic insurance risks originating from mortality, disability, natural catastrophes etc.). In addition, Knispel et al. (2011) discuss "non-quantifiable risks" that are difficult or impossible to measure in a quantitative framework, such as political or operational risks.

The market-consistent value is then the cost of producing these uncertain cash flows. For component $A$, it is simple as we can directly find instruments in the capital market to replicate the cash flows and their prices define the value of the cash flow. Component $B$ is already more difficult to assess, as these instruments do not exist in the current capital market but will only be available in the near or far future - especially important e.g. for pension funds with expected cash flows reaching out to the next 50 or 60 years. Insurance companies cannot directly replicate these cash flows but have to wait and take a certain risk that the costs for replicating these cash flows will change in the future. In particular, this emphasizes that it is difficult or even impossible to consider a static valuation but that the problem is inherently dynamic. The last component $\mathrm{C}$ cannot be replicated at all and, as required by regulators, companies have to hold risk capital for being able to pay for (even extreme) fluctuations of this component.

\subsection{Calculating the market-consistent value}

For the valuation of insurance liabilities, it is necessary to consider the risk associated with components $B$ and $C$. Valuation approaches prescribed within regulatory frameworks roughly take the following form (see e.g. Möhr (2011), who refers to the Solvency II Framework Directive):

Market-consistent Value $=$ Best Estimate + Risk Margin, 
where the risk margin is derived from the cost of capital applied to future risk margins:

$$
\text { Risk Margin }=\operatorname{CoC} \times \sum_{t \geq 0} \frac{\mathrm{SCR}_{t}}{\left(1+r_{t}\right)^{t}}
$$

Here, CoC stands for the cost of capital, $\mathrm{SCR}_{t}$ is the solvency capital requirement for year $[t, t+1]$, and $r_{t}$ is the risk-free discount rate for $t$ years.

A number of recent papers in the actuarial and quantitative risk management literature ${ }^{1}$ critically discuss this approach and attempt to align it with financial and actuarial theory, where risk-adjusting best estimate valuations for insurance risk has a long history (Bühlmann, 1970). One key difficulty here is to disentangle the "financial" and "actuarial" components of a given cash flow, corresponding to components $\mathrm{A}$ and $\mathrm{C}$ above, to ensure market consistency. Another issue is the recursive notion of the risk margin, where risk associated with future capital holding is reflected in the capital level today as with component $\mathrm{B}$ above, to ensure time consistency. Interestingly, different authors relying on alternative approaches arrive at so-called two-step valuation procedures, where an actuarial valuation is applied after conditioning/hedging the financial component (Pelsser and Stadje, 2014; Dhaene et al., 2017; and Engsner et al., 2017).

But even though these papers provide important insights on how to carry out the calculation conceptually, especially for components $B$ and $C$ the value depends heavily on assumptions on future management actions, models of how capital markets are going to change in the future, and models of how the randomly fluctuating cash flows will behave. These models and the assumptions needed to calibrate these models have to fulfill certain criteria as set by the regulators (e.g. in the risk management frameworks Solvency II and the Swiss Solvency Test). But across companies, management will act differently based on different business strategies, and also the models and parameters of the risk models differ as the portfolio and risk exposure in these companies is different. Consequently, it is impossible to define the one and only valuation model for insurance. Hence, while valuation is important for internal steering, it is very difficult to compare and interpret results across different companies.

Furthermore, in view of the usage for internal steering, the economic foundation for relying on given exogenous inputs that are supplied in some regulatory directives is murky. For instance, why should it be optimal to steer an insurance enterprise using a $99.5 \% \mathrm{VaR}$ as required in Solvency II? What is the economic rationale for relying on Value-at-Risk, how does it connect to the company's business objectives, and why is the $99.5 \%$ cut-off appropriate? And why should capital suppliers expect a constant $6 \%$ cost of capital rate as specified within Solvency II? More broadly, is it suitable to rely on an "arbitrary, exogenously specified constant figure" (Tsanakas et al., 2013)? For further discussion in this direction, see also Albrecher et al. (2017).

\subsection{Policy aspects for improving valuation: increasing transparency}

\footnotetext{
${ }^{1}$ See Kupper et al. (2008), Knispel et al. (2011), Möhr (2011), Tsanakas et al. (2013), Pelsser and Stadje (2014), Dhaene et al. (2017), and Engsner et al. (2017), among others.
} 
It does not seem reasonable to force all insurance companies into one global valuation framework. Market features, product design, future management actions, and policyholder behavior are too different in order for such an approach to result in a framework that can still be used to steer companies. However, for being able to compare results of different companies, more transparency on the models and assumptions, and more consistency on the assumptions of the capital market model would be helpful.

The first step for increasing transparency would be to apply a consistent framework for the capital market for the comparison of valuation results as a sensitivity. It is already a requirement in the Solvency II environment that certain long-term guarantee (LTG)-measures and transitionals ${ }^{2}$ may be applied for the calculation of the Solvency Capital Requirements, but have to be switched off for a European wide consistent and comparable scenario.

Second, it would be important to be more transparent on the uncertainties and risks in guarantees provided into the far future. ${ }^{3}$ One way could be to also calculate capital requirements specifically for these risks, and to report these additional requirements and the effect on valuation (via risk margin) and capital needs (via higher capital requirements and/or risk margin) as an additional sensitivity. Management action or product features that mitigate these risks should be made transparent by a qualitative assessment and they should also be considered in the sensitivity.

Unfortunately, a certain remaining lack of transparency of valuation results based on implicit assumptions on management/policyholder behavior and parameters used to calibrate cannot be avoided. It would not be possible to publish the entire valuation model or even the most relevant parts of it to the public: on the one hand, it is too complex to be understood even by experts not working on the model for a longer period of time, and, on the other hand, the model also includes future management action that cannot be made public for antitrust legislation, which would put the management in a bad position for negotiations and capital market transactions. Nevertheless, we believe that increasing the transparency is one of the key policy angles related to valuation.

\subsection{Research aspects for improving valuation: providing economic foundations}

In conventional financial-economic theory with frictionless markets, risk adjustments arise, if at all, due to the impact of a risk on aggregate consumption. Risk penalties will be diversified or arbitraged away, so that economizing on capital becomes "inappropriate" (Phillips, Cummins, and Allen, 1998). In company-level models with financing frictions and where a

\footnotetext{
2 For more information on LTG measures and transitionals, please refer to https://eiopa.europa.eu/GuidelinesSII/EIOPA_EN_LTG_GLs.pdf and delegated act 2015/35, 2016/467, and 2016/2283 of the European Commission.

${ }^{3} \mathrm{~A}$ few papers propose means of increasing transparency by including restrictions on the dynamic calculation of the risk margin. For instance, Engsner et al. (2017) propose to replicate shortfalls from components $B$ and $C$ with cash only, so that the strategy replicating component A remains "static" in the framework.
} 
liability cannot be hedged in a frictionless way, on the other hand, a value-maximizing company's valuation of the liability will include a company-specific risk penalty similar to Equation (1) above (Froot and Stein, 1998). This risk penalty will correspond to the origin of the company's capital holding. For instance, if the motivation for holding capital is risk aversion of the company's counterparties, Bauer and Zanjani (2016) show that it is possible to derive a risk measure that is in line with company profit maximization-although this risk measure has an unconventional form and does not necessarily satisfy frequently imposed risk measure axioms.

However, the economic foundations of how these frictional costs should be incorporated in the company's valuation model and how they arise in the first place are not well understood (Bauer et al., 2013). While the evolving literature on the impact of financial frictions on asset pricing (see e.g. Brunnermeier et al., 2012) demonstrates their relevance, so far few papers have spelled out the connection to the valuation of insurance liabilities. An exception is the paper by Duffie and Strulovici (2012), who show that in a setting where transferring capital to different markets is subject to intermediation frictions, capital costs arise endogenously and are reflected in valuation. In particular, in Appendix $D$ to their paper, the authors present a version of their model that is motivated by catastrophe insurance valuation. But despite these recent advances, a significant gap remains between financial theory and the valuation models as they are implemented in the insurance industry. We believe a key direction for future research is closing this gap. Pinpointing the economic origin of the components in the company's valuation equations will provide guidance on their calibration, and will enable to successively improve the valuation framework.

\section{Innovations in insurance products}

Given the current financial environment and new regulatory requirements, savings culture is discouraged, customers show a lower interest in life insurance products and insurance companies face high pressure on their portfolios with guarantees. In the following, we focus our discussion on three major aspects, namely, the future of investment guarantees, the life insurance model and transaction costs, and the regulation and its influence on insurance products.

\subsection{Investment guarantees}

Participating life insurance contracts, as well as several unit-linked products contain investment guarantees for their customers in the savings component of the treaty. Besides cliquet-style options, which are the most common forms of guarantees in participating life insurance contracts in Europe, we also find point-to-point put options, where a minimum payback is guaranteed at the end of the contract's maturity (additional paybacks are provided in case of death of the insured person or if surrender of the contract takes place). The pricing of this kind of guarantees is usually based on the risk neutral valuation technique of options in an extended Black-Scholes model setup.

In the current low interest rate environment, long-term investment guarantees are hard to finance. On the one hand, insurance companies still have contracts in their portfolios with high interest rate guarantees, which exceed the current riskless rate of return by far. On the 
other hand, zero or negative interest rate guarantees may not be interpreted as "value added" from the costumer's point of view and hence, their willingness to pay for such guarantees could be much lower than the "fair" price (based, e.g., on a risk neutral valuation framework, cf. Gatzert et al., 2012).

The risk of long term investment guarantees cannot be fully hedged by the insurer since adequate and default free risk management instruments, which correspond to components $B$ in Section 2.1, are typically missing (for instance, put options traded on the capital market with proper durations). Hence, one major problem is to deal with model and parameter risk, see also Section 5 below. These risk sources must - at the very end - be reflected in additional loadings to the "fair" price of such investments, such as in (1).

Even if a minimum payout at the end of maturity is provided to the policyholder, the present monetary value of such a promise (denoted in nominal terms) is hard to quantify from the customer's perspective. This point raises two issues. First, such investment guarantees could in general be related to the inflation rate; however, the future development of the market is unknown and the insurer must be paid for the additional risk bearing. Second, the question about the willingness to pay for various forms and levels of investment guarantees from the policyholder's point of view seems to be central in order to explain the use of these important product features. In any case, we would expect that the willingness to pay for investment guarantees should exceed the "fair" put option price in order to explain the existence of a proper market.

When it comes to cliquet-style options - which are for instance required in the second pillar products in Switzerland provided by life insurance companies - decision theory can in general not explain a demand for such guarantees. This point does not only hold true for normativerational decision makers (e.g., by assuming expected utility maximizing customers), but also if concepts from prospect theory like CPT (Cumulative Prospect Theory) or MCPT (Multi Cumulative Prospect Theory) are applied (cf. Russ and Schelling, 2017, and Braun et al., 2017). However, very little research has been delivered so far about an empirical foundation in respect to the policyholder's willingness to pay for investment guarantees. The reason for this research gap can be explained by the fact that direct questioning is in general not the right tool to get stable results for the question at hand. However, a choice-based-conjoint analysis could be the appropriate technical instrument to derive real willingness to pay for investment guarantees for different customer groups (cf. Braun et al., 2016). This information is helpful for insurers to offer appropriate guarantee forms and levels to particular customer groups and to extend the insurer's product portfolio.

Beside personal preferences whether to buy a product with an investment guarantee or not, the situation may be different in the context of compulsory pension schemes (like the second pillar in the Swiss old age provision system). Even if utility is reduced for some policyholder groups given the current investment guarantee setting, general economic aspects may play a role too: The government wants to reduce the risk of poverty among elderly and avoid a socialization of potential costs in this respect within the society.

In order to reduce guarantee costs for policyholders (which lead to a reduction in the product performance) and the risk for the insurer, different concepts of alternative more flexible 
guarantee forms can be introduced. One idea is to link the guarantee level to the future development of the term structure. Clearly, the adjustment mechanism at particular points in time (for instance every two years) must be made transparent to the policyholders when signing the contract. Another solution could allow the policyholders to decide each year if a put option at a particular level should be financed out of the savings or not. Assuming that put options are available on the capital market with respect to the relevant underlying, the guarantee promise is always fulfilled, the pricing of the guarantee is transparent, and the insurer faces no risk from the investment guarantee.

Besides investment guarantees, various forms of dynamic portfolio selection strategies (like portfolio insurance or volatility target strategies) could also work as alternatives. These concepts may face some disadvantage like a "lock in" effect (in the case of portfolio insurance) and cannot fulfil a minimum payoff under all circumstances, but typically produce much lower risk management costs - with positive effects on the performance of the savings part of the life insurance contract. And of course, one should not forget about "lessons learned from the past" when (re)introducing such strategies, e.g. it pays to reconsider the role played by portfolio insurance leading up to the 1987 crisis as a quick web-search will reveal.

\subsection{The life insurance model and transaction costs}

Next to the offer of some kind of financial guarantee, the "value added" that a life insurance company can provide to their customers is the coverage of biometric risks. The policyholders themselves cannot obtain the diversification of mortality risk. This is a unique selling point of most insurance products when compared to other financial investment products offered by banks for example. In general, it can be assumed that mortality risk can be fully diversified (and hence is purely unsystematic) since there may not be any significant interrelations to other risk factors. When it comes to savings, insurance companies are in competition with a large variety of different providers on the market (banking industry, mutual funds, ETF (exchange-traded fund) market). Besides guarantee costs, an important element is represented by transaction costs in the savings components of life insurance treaties and its negative impact on performance. On the one hand, in the current low interest rate environment, transaction costs become much more obvious (returns and surplus participation in savings contracts often do not cover the guarantee, distribution and administration costs, cf. Schmeiser and Wagner, 2016). On the other hand, particularly the traditional sales model of the life insurance industry (personal sales through tied agents or brokers receiving provisions) produces rather high transaction costs. Hence, in order to offer an attractive performance of the savings component, insurance companies may tend to use distribution channels with low costs (like online platforms) and offer combinations of ETFs in order to cope with different policyholder's preferences.

\subsection{Regulation}

Both cost elements - investment guarantee costs and transaction costs - play an important role when it comes to the influence of regulation on the general product design in the insurance sector. New solvency regimes like Solvency II and the Swiss Solvency Test require insurance companies to hold additional equity capital for long-term investment guarantees 
and for duration mismatching (Schmeiser and Wagner, 2015). Since a risk-adequate return on this equity capital can hardly be obtained in the current market situation, insurance companies will certainly try to reduce their obligations in this area. Solvency and investment regulations may also lead to wrong incentives regarding the asset allocation disallowing insurance companies to extract liquidity premiums (Persaud, 2015).

New regulatory attempts like the Insurance Distribution Directive (IDD) require insurance companies to provide more transparency about the distribution of the premiums to different product parts. In this context, profit margins, transaction costs and the pricing of different product features become much clearer to customers. In any case, we expect that - in combination with the digitalization trend - these developments would lead to much more pressure on the insurance industry to reduce transaction costs in general and sales costs in particular.

Current trends for the traditional insurance products mostly come with a reduction of guarantees and options, a massive restructuring of variable annuities and volatility controlled dynamic asset allocation. In the end, however, the following strategic questions must be addressed: Is it possible to achieve capital efficiency without abandoning core features of the products? How can insurers create and demonstrate upside potential to customers and link this to the existing willingness to pay? Here, all aspects of traditional products are targets for adjustments (e.g., the guaranteed amount after the accumulation phase, the handling of profit participation, the surrender values and annuity option) and capital savings can be substantial for insurers. In contrast to the above trend that may entail a reduction of life insurance volumes and profit margins, a trend that aims at filling the life insurance protection gaps comes with a rising awareness and extension of insurance risk cover, particularly in the areas of health and long-term care insurance. In many countries, the product landscape is extremely limited (e.g. for long-term care) and action is needed to face the given demographic evolution.

\section{Investments}

The primary purpose of the investment business of an insurance company is to meet its future liabilities, i.e. to be able to create the payments promised to its customers. A secondary issue is the creation of a decent surplus to satisfy both customers and shareholders. As the matching of the liabilities has higher priority, an insurance company should tailor its investment strategy to fulfil this issue. A traditional, but not very detailed investment rule therefore requires that the duration of the assets and the liabilities of an insurance company should be matched. From this rule, there is a genuine motivation for insurance companies particularly life insurers - to invest into assets with a long duration, often into those with the longest duration available as the liabilities to be matched typically exceed the time horizon of the investment opportunities. It can also cause pro-cyclical investment behaviour.

\subsection{Illiquid assets}

Although assets with a high duration need not necessarily be illiquid ones, they are often associated with illiquid investments such as infrastructure, loans, windparks, or real estate. 
Especially in the recent very low interest rate setting, insurers often claim that they are able to generate a stable series of returns above the riskless rate due to the fact that they can hold illiquid positions until their duration and thereby receive an additional illiquidity premium. This of course is a desirable secondary issue next to the matching of the duration between assets and liabilities.

However, the primary issue of matching the evolution of assets and liabilities is typically only dealt with in a very rudimentary way, sometimes only in the form of the request to the asset side to "try to generate as much return as possible".

Methods from continuous-time portfolio optimization are often considered to be of academic interest only. However, motivated by the Solvency II requirements, there has been active recent research in the area of replicating portfolios offering new approaches to link assets and liabilities (see e.g. Cambou and Filipovic, 2017a, Natolski and Werner, 2014, or Pelsser and Schweizer, 2015). Here, replication is considered in the sense of mimicking the dynamic behaviour of the liabilities as well as possible, since it is clear that there cannot be a complete replication of the liabilities by market assets. Given a sufficiently good matching of the optimal replicating portfolio and the liabilities, the liabilities can approximately be assumed to be tradable. They can then enter the task of the asset side by setting up an investment problem under constraints similar to the setting of Korn (2005). Thus, an optimal trading strategy on the asset side can include side constraints such as always being able to generate a final wealth (at a given time horizon) which at least covers the liabilities (as represented by the evolution of the replicating portfolio). Such a strategy would for instance eliminate the shortfall risk.

At the same time, it is important to find appropriate models for the characteristics and the dynamic behaviour of illiquid assets. A particular issue is the mechanics of pricing haircuts in the case of forced sales due to liquidity shocks. Given those threats there should exist a compensation for the buyer of illiquid assets in form of an illiquidity premium. Liquidity characteristics should hence enter the portfolio decision already when the asset mix is decided. This also has to be seen in light of the fact that short and long-term objectives of an institutional investor may be in conflict with each other. Suggested models for illiquidity (premiums or costs) can occur exogenously in form of transaction fees or an assumed percentage loss of the accounting value when a sale is forced. One can also think of illiquidity as a consequence of information asymmetry which would be an endogenous approach.

\subsection{Pro-cyclical investment behaviour}

A further crucial topic is how to avoid pro-cyclical investment behaviour. As an example, spread widening due to a worsening in market liquidity on bonds matching liabilities does not impact the claims paying ability of the insurer. It should therefore not trigger asset sales across the insurance industry to prevent pro-cyclical investment behaviour. In terms of pro-cyclical investment behaviour, there are three areas to focus on:

- Illiquidity: Looking at the optimal mix in the replicating portfolio, one observes that the higher the illiquidity issue in a portfolio the smaller should be its optimal part in the mix inside the replicating portfolio. 
- Risk tolerance: The existence of a counter-cyclical buffer to account for liquidity shocks in the valuation of the assets and a valuation adjustment for volatility makes the insurer more robust with respect to Solvency II sensitivity for a 100 bps corporate credit spread change.

- Risk measurement: The question is if there is sufficient evidence for mean-reversion that can be used for modelling the dynamic behaviour of spreads and which would be an argument for omitting pro-cyclical investment behaviour.

The illiquidity premium is a rather controversial concept (for a critical actuarial discussion on the integration of an illiquidity premium into best estimates of insurance liabilities, see Wüthrich, 2017). It certainly is not a justification for the current push into long term illiquid instruments. The hunt for yield in times of low interest rates can be seen as the fundamental reason to invest in illiquid assets. However, it is clear that risk increases exponentially when the exposure to illiquidity is increased. Further, the asset class of illiquid investments is very diverse and requires a lot of different competences and knowledge about such issues as political risk, valuation of infrastructure investments or country risk.

There is definitely need for further research on

- models for illiquid assets,

- a rational argument for the possibility and size of an illiquidity premium,

- proper risk quantification of investment in illiquid assets,

- empirical checks of the models.

The issue of automatic de-risking is closely related to the issue of pro-cyclical investment behaviour. An often-raised problem is the non-symmetric treatment of risk buffers. While surplus earned on market risk is often used to give capital back to shareholders, negative performance trends do not lead to capital injections by the shareholders. The typical consequence of negative trends is de-risking, so again an issue of pro-cyclical investment behaviour. On the other hand, there is an agreement on the belief that a high solvency ratio leaves space to avoid pro-cyclical de-risking. A challenge in this direction is the transparency about the solvency ratio, as discussed in Section 2.3. A temporary decline of it can possibly lead to a loss in reputation of the insurer. There is a need for theoretical and empirical investigation of the performance and exact form of such buffer strategies. Why does an insurer take market risk at all? Arguments in favour are the possibility of an insurer to carry losses forward and therefore benefit on taxes and the possibility for shareholders to have a cheap access to leverage via insurance stocks. On the down side, losing too much on market risk means also that the insurer loses risk-taking capacity in its core business. Thus, there is a significant demand for a solid modelling of the optimal market risk position that an insurer should have, as well as for upper bounds of market risk for an insurer to have sufficient risk capacity for the core business. Solutions to these problems would also have substantial impact on the insurers' investment behaviour and stability of society as a whole.

\section{Models}

The asset-liability management for long-term insurance relies substantially on models due to a lack of a liquid market for long-term assets as well as liabilities. Among the many important 
aspects in this connection, in the following we focus on six issues, namely, the Smith-Wilson method for constructing the discount curve, the robustness of optimal investment policies, the trade-off between complexity and manageability of models, the calibration of interest rate volatility, what-if scenario analyses and the quantitative impact of management rules.

\subsection{The Smith-Wilson method}

As seen in Section 2, for various purposes, such as reporting for Solvency II, insurance companies and pension funds have to determine the market value of the assets and liabilities on their balance sheets. Future promised payments that are certain must be valued by discounting these payments with a risk-free term-structure of interest rates. EIOPA uses the Smith-Wilson method to construct a risk-free curve. The parameterisation chosen by EIOPA builds on the following principles:

- Market prices for swap contracts are not used for maturities beyond 20 years.

- Instead, interest rates are converging towards an "ultimate forward rate" which is significantly higher than the observed market rates.

- A risk premium is added on top of the observed risk-free rates.

All these adjustments are illustrated in Jorgensen (2017), where he compares the official EIOPA risk-free curve for DKK with a horizontally extrapolated swap curve. Under current market conditions, the EIOPA risk-free rates exceed the extrapolated swap rates by more than 100 bps on time horizons beyond 30 years. It remains to be investigated to what extent this spread can be explained by economic determinants, including market distortion caused by the quantitative easing of central banks, market illiquidity, and amplification mechanisms such as the hunt for duration, see Domanski et al. (2017).

\subsection{Model ambiguity}

The traditional approach to optimal investment policies is to formulate an economic model and an objective function, and then compute the optimal strategy that maximises the objective function.

Although this is mathematically sound, it turns out that the optimal strategy can often be extremely sensitive to the underlying model assumptions. This can be problematic in economics where models are inaccurate or, phrased differently, are subject to model ambiguity. We consequently see in practice that many strategies that are mathematically optimal perform quite poorly in the real world.

One approach to deal with the problem, is to take the model ambiguity explicitly into account when designing a strategy. The idea is to find strategies that perform reasonably well under multiple models. Hence, we obtain strategies that are more robust against model misspecification and are still able to achieve the desired objective. This approach has generally been advocated for economic decision-making in Hansen and Sargent (2008). For a discussion on robustness properties related to risk allocation between several agents, see for instance Embrechts et al. (2017). The latter paper also discusses robustness issues related to the regulatory environment in force. 


\subsection{Model complexity and manageability}

When trying to capture all the risks in a book of insurance products, one needs to capture a wide range of external (such as interest rates and mortality) and internal (such as management decisions) risk drivers. Furthermore, all these risks need to be aggregated. It is crucial to address the imperfectness of the models and their sensitivities. A major challenge in this context is to find an appropriate compromise between using different models for different products and/or applications and at the same time maintain a high level of consistency for the overall outcomes. In addition, the right balance between simplicity and accuracy of the used models needs to be identified. The emphasis on scenario analysis is then also to be decided upon, together with the question on how realistic the used scenarios are. For some concrete discussions, see for instance McNeil and Smith (2012), Embrechts et al. (2015), as well as Cambou and Filipovic (2017b).

\subsection{Yield curve volatility}

Yield curves are used by insurers for various objectives. As any modelling choice, the choice of the volatility surface for yield curves should depend on the purpose for which it is used. Insurers tend to use the implied volatilities measured at the end of the calendar year to make their computations for Solvency II or the Swiss Solvency Test. El Karoui et al. (2017) underpin the fact that markets are particularly different from the rest of the year at that time, because of the numerous end-of-year adjustments made by market players. Using the end-of-year volatilities is in line with time and involves less expert judgment than other solutions, but is not representative of all available data. One alternative is to use an averaged volatility surface. It involves more expert judgment, might underestimate the risk in some cases, but would be less biased by the end-of-year effect. Another possibility is to perform the calibration at another date (end of October, say). This would accelerate computations and avoid the endof-year bias. However, it would not be "market-consistent" and could miss some important event that may occur until the end of year. Using historic volatilities instead of implied volatilities could reduce balance sheet volatility but could lead to an important underestimation of risk, even more so than the average volatility surface. In any case, one must keep in mind that volatilities are strongly dependent on the level and that displacing yield curves without volatility adjustment may breed large errors.

\subsection{What-if scenarios}

What-if scenarios are part of the Own Risk and Solvency Assessment (ORSA) process and are used for different purposes. They may have an inferential objective in cases where it is hard to develop an extreme value theory model, or an educational objective: showing the potential effect of an event on the company's balance sheet might be much more powerful to make board members realize the importance of some concentration risk than some modelling approaches that would suffer criticism and scepticism due to model uncertainty. They can be helpful for managerial decision making like de-risking or diversification. Reverse stress tests are particular scenarios that help decision makers understand better the level of resilience of 
the organization. What-if scenarios might be studied for additional regulatory reasons or to reflect on topics like inter-generational fairness and understand better how money may flow from one age group to another. The scenario construction is highly dependent on the purpose, and expert judgment governance as well as consistency of risk map scenarios are important components of the risk management process. One should not forget to consider combined events and contagion effects. The conditional world (given that this precise scenario occurs) should be carefully analysed in order to avoid a false impression of conditional safety.

\subsection{Management rules}

Internal models of insurance companies must take into account management rules. There should be sensitivity testing with respect to management actions, as they often have more impact on the final outputs of the model than some correlation parameters for example. One problem is that if a company wants to make a model change in Solvency II, it should plan six months in advance at least. The governance about management rules has a significant impact: these questions must be discussed with the management and a sign-off must be obtained. More precisely, the top management will need to know how the model reacts to different management rules. Parameters for management actions may be of technical nature or discretionary. Of course, the management actions model is not binding: decision makers may decide to take another option than what they had claimed that they would do if the situation occurred. However, the regulator will at least check evidence that management rules are not contradictory with respect to decisions made in the past without a proper explanation. Regulators have observed very heterogeneous management rules from one company to the other and standardization starts to be discussed. In too many cases, modelled management actions reflect more the views of the Chief Risk Officer than the ones of the Chief Executive Officer and of the Chief Financial Officer. Emphasis should be put on a better understanding of the consequences of management actions as well as their dynamic nature.

About the Swiss Risk and Insurance Forum. The Swiss Risk and Insurance Forum was created in 2014 with the mission to bring together experts from academia, the insurance industry, regulatory bodies and consulting companies to discuss (typically technical) topics that are relevant to the insurance industry. The main objective is to provide a platform on which people from academia can interact with those involved on the more practical side of the insurance industry. This shall facilitate the knowledge transfer in both directions helping enrich the research agendas of the academic institutions and enabling those dealing with practical matters to partake in the newest academic developments. The 2017 workshop on asset-liability management for long-term insurance business gathered 36 experts for two days of presentations and discussions.

More information can be found at

http://institute.swissre.com/events/Swiss_Risk_and_Insurance_Forum_2017

Acknowledgements. We thank Stephan Schreckenberg for suggesting the format of the conference, and for his critical and active support in the creation of the Swiss Risk and Insurance Forum. We thank all participants for the stimulating and lively discussion:

Albrecher Hansjörg, University of Lausanne

Bailly Alexis, Moody's Analytics 
Bauer Daniel, Georgia State University

Embrechts Paul, ETH Zurich and Swiss Finance Institute

Filipovic Damir, EPFL and Swiss Finance Institute

Germann Hansjörg, Zurich Insurance

Grützner Guido, QuantAkt

Guerin Jean-Francois, Swiss Life

Harrison Glenn, Georgia State University

Jäger Jan, Swiss Re

Jaschke Stefan, Infinada

Joos Pierre, Allianz

Jorgensen Peter Lochte, University of Aarhus

Kalberer Tigran, Milliman

Keller Philipp, Deloitte

Koch Pablo, University of Zurich

Korn Ralf, TU Kaiserslautern

Kunz Andreas, Munich Re

Leukert Renate, Swiss Re

Loisel Stéphane, Université Lyon 1

Moeller Thomas, PFA and University of Copenhagen

Pelsser Antoon, Maastricht University

Popp Markus, Munich Re

Schätti Guido, Swiss Re

Schiller Frank, Munich Re

Schmeiser Hato, University of St. Gallen

Schmutz Michael, Finma and University of Bern

Schreckenberg Stephan, Swiss Re

Singh Raj, Standard Life

Smith Andrew, Deloitte

Steiger Gallus, Swiss Re

Tommasina Tancredi, Swiss Life

Wagner Joël, University of Lausanne

Weber Frank, PwC

Werner Ralf, University of Augsburg

Wilson Tom, Allianz

The Swiss Risk and Insurance Forum 2017 received financial support from Swiss Re, Swiss Life, the Swissquote Chair in Quantitative Finance at EPFL, the ETH Risk Centre and RiskLab, the Center for Finance and Insurance at the University of Zurich and the Department of Actuarial Science of the University of Lausanne.

\section{References}

Albrecher, H., K. Eisele, M. Steffensen, and M.V. Wüthrich, 2017, A framework for cost-ofcapital rate analysis in insurance, University of Lausanne, Preprint. 
Albrecher, H., P. Embrechts, D. Filipovic, G. Harrison, P. Koch, S. Loisel, P. Vianini, and J. Wagner, 2016, Old-age provision: past, present and future, European Actuarial Journal 6(2), 287-306.

Bauer, D., R. Phillips, and G. Zanjani, 2013, Financial pricing of insurance, Handbook of Insurance, 627-645. Springer, New York.

Bauer, D., and G. Zanjani, 2016, The marginal cost of risk, risk measures, and capital allocation. Management Science 62(5), 1431-1457.

Braun, A., M. Fischer, and H. Schmeiser, 2017, Saving for retirement in a low interest rate environment: are life insurance products good investments?, University of St. Gallen, Preprint.

Braun, A., H. Schmeiser, and F. Schreiber, 2016, On consumer preferences and the willingness to pay for term life insurance, European Journal of Operational Research, 253(3), 761-776.

Bühlmann, H., 1970, Mathematical Methods in Risk Theory. Springer, Berlin.

Brunnermeier, M.K., T. Eisenbach, and Y. Sannikov, 2013, Macroeconomics with financial frictions: a survey. Advances in Economics and Econometrics, Tenth World Congress of the Econometric Society. Cambridge University Press, New York.

Cambou, M., and D. Filipovic, 2017a, Replicating portfolio approach to capital calculation, Finance \& Stochastics, in press.

Cambou, M., and D. Filipovic, 2017b, Model Uncertainty and Scenario Aggregation, Mathematical Finance 27(2), 534-567.

Dhaene, J., B. Stassen, K. Barigou, D. Linders, and Z. Chen, 2017, Fair valuation of insurance liabilities: Merging actuarial judgement and market-consistency. Insurance: Mathematics and Economics 76, 14-27.

Domanski, D., H.S. Shin, and V. Sushko, 2017, The Hunt for Duration: Not Waving but Drowning? IMF Econ Rev 65(1), 113-153.

Duffie, D., and B. Strulovici, 2012, Capital Mobility and Asset Pricing. Econometrica 80(6), 2469-2509.

El Karoui, N., S. Loisel, J.L. Prigent and J. Vedani, 2017, Market inconsistencies of the marketconsistent European life insurance economic valuations: pitfalls and practical solutions. European Actuarial Journal, 7(1), 1-28.

Embrechts, P., H. Liu, and R. Wang, 2017, Quantile-based risk sharing. Operations Research, in press.

Embrechts, P., B. Wang, and R. Wang, 2015, Aggregation-robustness and model uncertainty of regulatory risk measures. Finance and Stochastics, 19(4), 763-790. 
Engsner, H., M. Lindholm, and F. Lindskog, 2017, Insurance valuation: A computable multiperiod cost-of-capital approach. Insurance: Mathematics and Economics 72, 250-264.

Froot, K.A., and J.C. Stein, 1998, Risk management, capital budgeting, and capital structure policy for financial institutions: an integrated approach. Journal of Financial Economics 47(1), 55-82.

Gatzert, N., I. Holzmüller, and H. Schmeiser, 2012, Creating Customer Value in Participating Life Insurance, Journal of Risk and Insurance, 79(3), 645-670.

Hansen, L. P., and T.J. Sargent, 2008, Robustness. Princeton University Press.

Jorgensen, P.L., 2017, An Analysis of the Solvency II Regulatory Framework's Smith-Wilson Model for the Term Structure of Risk-free Interest Rates. Aarhus University, Preprint.

Knispel, T., G. Stahl, and S. Weber, 2011, From the Equivalence Principle to Market Consistent Valuation. Jahresbericht der Deutschen Mathematiker-Vereinigung 113, 139-172.

Koch-Medina, P., M. Cambou, and C. Munari, 2014, Expert Forum on "Risk Measures and Regulation in Insurance". University of Zurich.

http://media.swissre.com/documents/Summary_of_research_topics1.pdf

Korn, R., and M. Krekel, 2002, Optimal portfolios with fixed consumption or income streams, Berichte des Fraunhofer ITWM 31.

Korn, R., 2005, Optimal portfolios with a positive lower bound on final wealth, Quantitative Finance 5(3), 315-321.

Kupper, M., P. Cheridito, and D. Filipovic, 2008, Dynamic risk measures, valuations and optimal dividends for insurance. In Mini-Workshop: Mathematics of Solvency. Mathematisches Forschungsinstitut Oberwolfach.

McNeil, A. J., and A.D. Smith, 2012, Multivariate Stress Scenarios and Solvency, Insurance: Math. Econ. 50(3), 299-308.

Möhr, C., 2011, Market-Consistent Valuation of Insurance Liabilities by Cost of Capital. ASTIN Bulletin 41(2), 315-341.

Natolski, J. and R. Werner, 2014, Mathematical analysis of different approaches for replicating portfolios, European Actuarial Journal 4(2), 411-435.

Pelsser, A., 2003, Pricing and hedging guaranteed annuity options via static option replication, Insurance: Mathematics and Economics 33(2), 283-296.

Pelsser, A., and J. Schweizer, 2015, The difference between LSMC and replicating portfolio in insurance liability modelling ricing and hedging guaranteed annuity options via static option replication, European Actuarial Journal 6(2), 441-494.

Pelsser, A., and M. Stadje, 2014, Time-consistent and market-consistent evaluations. Mathematical Finance 24(1), 25-65. 
Persaud, A., 2015, How Not to Regulate Insurance Markets: The risks and dangers of Solvency II, Peterson Institute of International Economics, Policy Brief 15-5.

Phillips, R.D., J.D. Cummins, and F. Allen, 1998, Financial pricing of insurance in the multipleline insurance company. Journal of Risk and Insurance 65(4), 597-636.

Ruß, J., and S. Schelling, 2017, Multi cumulative prospect theory and the demand for cliquetstyle guarantees, Journal of Risk and Insurance, in press.

Schmeiser, H., and J. Wagner, 2015, A proposal on how the regulator should set minimum interest rate guarantees in participating life insurance contracts, Journal of Risk and Insurance, 82(3), 659-686.

Schmeiser, H., and J. Wagner, 2016, What transaction costs are acceptable in life insurance products from the policyholders' viewpoint?, Journal of Risk Finance, 17(3), 277-294.

Tsanakas, A., M.V. Wüthrich, and A. Cerny, 2013, Market value margin via mean-variance hedging. ASTIN Bulletin 43, 301-322.

Wüthrich, M.V., 2011, An academic view on the illiquidity premium and market-consistent valuation in insurance. European Actuarial Journal, 1(1), 93-105. 